\title{
Does the single-item self-rated health measure the same thing across different wordings? Construct validity study
}

\author{
Stéphane Cullati ${ }^{1,2,3,4}$ (D) Naike Bochatay ${ }^{2,5,6} \cdot$ Clémentine Rossier $^{7} \cdot$ Idris Guessous $^{8} \cdot$ Claudine Burton-Jeangros $^{2}$. \\ Delphine S. Courvoisier ${ }^{3,4}$
}

Accepted: 13 May 2020 / Published online: 20 May 2020

(c) The Author(s) 2020

\begin{abstract}
Purpose The self-rated health (SRH) item is frequently used in health surveys but variations of its form (wording, response options) may hinder comparisons between versions over time or across surveys. The objectives were to determine (a) whether three SRH forms are equivalent, (b) the form with the best construct validity and (c) the best coding scheme to maximize equivalence across forms.

Methods We used data from 58,023 respondents of the Swiss Health Survey. Three SRH forms were used. Response options varied across forms and we explored four coding schemes (two considering SRH as continuous, two as dichotomous). Construct validity of the SRH was assessed using 34 health predictors to estimate the explained variance.

Results Distributions of response options were similar across SRH forms, except for the "good" and "very good" options ("good" in form 1: $58.6 \%$, form 2: $65.0 \%$ and form 3: 44.1\%). Explained variances differed across SRH forms, with form 3 providing the best overall explained variance, regardless of coding schemes. The linear coding scheme maximised the equivalence across SRH forms.

Conclusion The three SRH forms were not equivalent in terms of construct validity. Studies examining the evolution of SRH over time with surveys using different forms should use the linear coding scheme to maximise equivalence between SRH forms.
\end{abstract}

Keywords Self-rated health · Questions wording · Response options · Construct validity · Population health measurement

Electronic supplementary material The online version of this article (https://doi.org/10.1007/s11136-020-02533-2) contains supplementary material, which is available to authorized users.

Stéphane Cullati

stephane.cullati@unifr.ch

1 Population Health Laboratory, University of Fribourg, Fribourg, Switzerland

2 Institute of Sociological Research, University of Geneva, Geneva, Switzerland

3 Department of Readaptation and Geriatrics, University of Geneva, Geneva, Switzerland

4 Quality of Care Service, Department of Readaptation and Geriatrics, Faculty of Medicine, University of Geneva, Chemin Thury 3, 1206 Geneva, Switzerland

\section{Key-points}

The self-rated health ( $\mathrm{SRH})$ item is frequently used in health surveys but variations of its form (wording, response options) may hinder comparisons between versions over time or across surveys

5 Department of Paediatrics, University of California, San Francisco, CA, USA

6 Unit of Development and Research in Medical Education, Faculty of Medicine, University of Geneva, Geneva, Switzerland

7 Institute of Demography and Socioeconomics, University of Geneva, Geneva, Switzerland

8 Division of Primary Care Medicine, Department of Primary Care Medicine, Geneva University Hospitals, Geneva, Switzerland 
SRH forms were not equivalent in terms of construct validity

Linear coding scheme of the SRH maximises the equivalence between forms.

\section{Introduction}

The self-rated health (SRH) item (also called self-assessed health or self-perceived health) is frequently used in demographic and population health surveys to capture respondents' self-reported general health. The success of this selfreported indicator is explained by its ease of use (a single question), its validity [1, 2] and reliability [3, 4]. Particularly, the SRH item predicts mortality [5, 6], use of health services [7] and health expenditures [7, 8] in large and representative surveys of the general adult population. Considering that the concept, or latent variable, measured by the SRH item is still not entirely clear [9], evidence suggests that the SRH item captures a broad range of health dimensions [10] — physical, mental and functional health [11, 12] — and health behaviours $[10,12]$, and reflects an enduring rating of one's health status [4]. The SRH item thus functions as an umbrella indicator of respondents' general health status.

What the SRH item measures may be sensitive to the wording of the question and the response options. Indeed, the SRH item allows respondents to assess their health status according to their own definition of health. The SRH item is also a comprehensive assessment of health in general rather than an inquiry about specific symptoms, illnesses or dysfunctions. Various phrasings of the question and response options (hereafter, "forms"), however, have been used in population health surveys. For examples, common phrasings include "Would you say your health is...", or "In general, how would you rate your health?" Common response options are "excellent/very good/good/fair/poor" or "very good, good, fair, bad, very bad", but can also range from three to five options. For an illustration of the variability of forms in large-scale, national and international, survey infrastructures, see Table S1. As the SRH item is among the most frequently used health measures in population health surveys, it is important to determine if different forms are equivalent $[13,14]$, specifically in terms of the association of the SRH item with specific health measures (construct validity).

Numerous countries monitor the evolution of the health status of their general population with repeated crosssectional surveys using the SRH item, but they often have changed its forms over time [15]. For example, the Swiss Health Survey (SHS) has conducted five repeated surveys between 1992 and 2012 and has modified the SRH item twice during this period (the phrasing of both the question and the response options), resulting in three different forms.
In such context, it is important to determine if changes in the SRH form alter what the SRH item actually measures. Variations in the question [15] and in response options [13, 14, $16,17]$ have been shown to alter the assessment of health; however, in the context of the SHS, both types of change (question and response options) are concurrent, a specific case which need to be evaluated. Here, we sought to examine (a) whether three forms of the SRH item in the SHS are equivalent in terms of construct validity and, if not, to determine (b) the form with the best construct validity and (c) the best coding scheme of response options to maximize equivalence across the three forms.

\section{Methods}

\section{Study design}

We used the SHS, a repeated, cross-sectional, nationally representative survey of residents 15 years and older living in Switzerland. The SHS surveyed participants in three languages (German, French and Italian), depending on their region of residency. The SHS was administered in 1992, 1997, 2002, 2007 and 2012 and the participation rates (the number of participants having participated divided by the number of people invited to participate in the survey) were $70.8 \%, 68.8 \%, 63.9 \%, 66.3 \%$ and $53.1 \%$, respectively. For the analyses, we excluded respondents aged less than $18\left(N=2^{\prime} 780\right)$, and used data from the remaining 58,023 respondents who participated in waves 2002, 2007 and 2012. The SHS data are anonymous and available upon payment of fees. Ethical approval has been obtained by the Swiss Federal Statistical Office.

\section{Self-rated health forms}

The three forms of the self-rated health item are detailed in appendix (Table S2).

\section{Coding schemes of response options}

We used four coding schemes of response options (Table S3). First, we coded response options as a binary variable with an emphasis on positive options: "very good, good" versus "middle/moderate/ relatively good, poor, very poor". This coding scheme was named "Dichotomised with positive focus". Second, we coded response options as a binary variable with an emphasis on negative options: "very good, good, moderate/relatively good" versus "poor, very poor". This coding scheme was named "Dichotomised with negative focus". Third, we treated response options as linear. Fourth, we "linearised" response options with an alternative coding scheme, by recoding response options 
with ratings values: $1,2,3.7,4.5$ and 5 , corresponding to an evenly spaced distance on a visual analogue scale [18]. Such transformation improves the interpretation of the mean values of SRH. This recoding has been developed for response options "excellent, very good, good, fair, poor" (three positive and two negative). This linearised coding scheme was applied to form 3, which was the only form to have adopted the "US form" for its responses, but not to forms 1 and 2 which response options were too different (two positive, one neutral, two negative). These four schemes are the most frequently used treatment of response options in health research [19-22].

\section{Health status variables}

The SRH item captures a range of health dimensions [10]. Several health status variables were grouped into four dimensions: physical health, mental health, functional health [11, 23, 24] and health behaviours [10]. The first three dimensions mirror the WHO definition of health, which is "a state of complete physical, mental and social well-being" [25]. Physical health variables included body mass index (BMI), back pains, headaches, cardiac irregularities, chest pain, diarrhoea or constipation, fever and stomach pain or bloating. They also included chronic disease variables such as treatment for allergies, bronchitis, cancer or a tumour, hypertension, kidney stones, mental breakdown, myocardial infarction, stroke and diabetes in the 12 months that preceded the survey. Mental health variables included feeling unable to overcome barriers, loss of control, feeling overwhelmed with problems, feeling tired or exhausted or without energy, and problems with sleeping. Functional health variables included needing assistance to walk, to read and to hear. Health behaviour variables included smoking (yes, no), frequency of alcohol consumption (never, once a day and less, twice a day, three times a day), physical activity during free time, eating fruits daily and eating vegetables daily.

Response options of physical, mental, functional health and chronic disease variables were re-coded as present (1) vs. absent (0). Respondents with missing information were imputed as 0 (absence). BMI was defined following the Quetelet definition $\left(\mathrm{kg} / \mathrm{m}^{2}\right)$. All these health status variables were used as predictors of SRH.

\section{Covariates of self-rated health}

We used the following known factors associated with SRH [19, 26-30]: age (continuous), marital status (single, married, widowed, divorced and separated), number of children younger than 15 years living in the household $(0,1,2,3$ and more), nationality (Swiss, other), education (primary, secondary, tertiary), household monthly income ( $\leq \mathrm{CHF}$ 2000, CHF 2001-4000, CHF 4001-6000, > CHF 6000), employment status, urban vs. rural area of residency, linguistic region (German, French, Italian), use of medicine in the last 7 days (yes, no) and having friends or relatives to discuss personal issues (yes, no). Employment status had three categories: out of the labour force (including student, unemployed, retired and others), employed full time, and employed part time. Household income was weighted with the number of persons living the household and the number of children less than 15 years old.

\section{Statistical analyses}

The three forms of SRH were used as dependent variables. Multivariable regression models were used to assess the contribution of health variables (thirty health status variables, representing thirty health predictors). Linear regression was used when the coding schemes were continuous (linear and linearised) and logistic regression when coding schemes were binary (dichotomous with positive focus and with negative focus). All models were adjusted with covariates of SRH. Age was included as a continuous variable. In sensitivity analyse, age was used as category for stratification purpose (see section Sensitivity analyses). We computed the percentage of explained variances using the adjusted $\mathrm{R}$ squared for the linear coding scheme, the MacKelvey and Zavoina pseudo R squared for the dichotomous coding schemes, and reported these percentage of explained variances for the overall model (all health status variables) and by health dimensions (physical health, chronic diseases, mental health, functional health, health behaviours). Analyses were conducted overall and separately for women and men because gendered differences in the production of selfrated health assessments [31, 32].

The three SRH forms were administered at different periods (2002, 2007 and 2012); thus, differences across SRH forms may reflect "true" differences in health status of the general population. To limit the impact of these different periods, all models were adjusted with covariates known to be associated with SRH [19, 26-30]: age, marital status, number of children, nationality (Swiss or foreign), education, income, employment status, living in urban or rural area, linguistic regions, use of medicine in the last 7 days, and having friends or relatives to discuss personal issues.

When the events per variable (EPV) were smaller than 10 , we did not estimate the model as they are known to produce incorrect estimates [33]. This occurred to the full model, including all covariates, and using the coding scheme "Dichotomised with negative focus" (out of 7300 patients, 320 had a value of very poor or poor and there were 45 predictors). However, we estimated the models using the coding scheme "Dichotomised with negative focus" for each health dimensions taken separately. 


\section{Sensitivity analyses}

First, we ran the same analyses on all waves of the SHS surveys, i.e. including waves 1992 and 1997 in which the SRH form was similar to form 1 (2002). Thus, the sample size for SRH form 1 increased to 20,873 men and 25,809 women. Second, we replicated the models stratifying by age groups: $18-35,36-59$ and $60+$. Health status ratings are age dependant $[9,34]$, as elderly people have been shown to be more optimistic [35-37]. Third, we replicated the models stratifying by education because evidence suggests that reliability of SRH may be lower among disadvantaged people $[38,39]$ and the meaning of rating may vary by education [34].

\section{Results}

\section{Participant characteristics}

The sociodemographic characteristics of participants were different across the three forms of SRH (Table 1 and Appendix S4). Distributions of response options across the three forms of SRH were similar (Fig. 1) with the exceptions of respondents reporting "good" and "very good" health: the proportion of respondents reporting "good" health was lower in form 3 (44.1\%) compared to forms $2(65.0 \%)$ and $1(58.6 \%)$. The proportion of respondents reporting "very good" health varied across forms 1, 2 and $3(25.0 \%, 19.5 \%$ and $37.8 \%$, respectively). Treated as a linear variable, the mean of the SRH item was 4.04 (95\% Confidence Interval (CI) 4.04-4.05) in form 1, 3.99 (95\% CI 3.98-4.01) in form 2 and 4.15 (95\% CI 4.14-4.16) in form 3. Adjusted for participants' characteristics (see list in Method section), the mean SRH depicted the same pattern across forms (4.06, 95\% CI [4.06-4.06]; 4.02, 95\% CI [4.02-4.03]; and 4.18, 95\% CI [4.18-4.19], respectively). Standard deviation (SD) was higher in form 3 (0.83) compared to form $1(0.75)$ and form 2 (0.71). These variations across SRH forms were similar for both men and women.

\section{Construct validity equivalence between three forms of SRH}

Thirty-four health status variables were used to predict the three SRH forms. The distribution of these variables across the three forms of SRH is reported in Table S5. Explained variances were estimated for three coding schemes (dichotomised with positive focus, dichotomised with negative focus and linear) in each form. Our fourth coding scheme ("linearised") was specific to form 3 (Table 2). Results showed that the largest difference (across the SRH forms) of overall explained variances was $3.8 \%$ for linear coding and
4.2\% for dichotomised with positive focus (dichotomised with negative focus was not estimated for the overall model). Across health dimensions, differences in explained variances across forms were less pronounced. We observed the lowest differences across forms for functional health (largest difference of explained variances less than $1 \%$ across coding schemes) and the highest for mental health (ranging 1.6-3.3\% across coding schemes). Differences across forms for the other health dimensions fluctuated with coding schemes (chronic diseases $0.2-1.3 \%$, physical health $0.4-1.9 \%$, health behaviours $0.5-2.5 \%$ ).

Similar patterns were observed when stratifying the results between men and women (Table $\underline{\mathbf{S} 6}$ ).

\section{SRH form with the best construct validity}

Form 3 had the best overall explained variance in linear (16.7\%) and dichotomised with positive focus (14.2\%) coding schemes (Table 2). Across health dimensions, form 3 frequently explained more variance compared to forms 1 and 2, except when SRH was dichotomised with negative focus. Results were similar when stratifying the results between men and women (Table $\underline{\mathrm{S} 6}$ ). In form 3 , the linearised coding scheme explained more variance compared to the other coding schemes, overall and across health dimensions.

\section{Associations between SRH form 3 linearised and health status variables}

Using a multivariable linear regression model, we further explored the associations between 34 health status variables and the SRH form having the best construct validity, i.e. form 3, coded "linearised" (Table $\underline{S 7}$ ). For both men and women, 26 health status variables were significantly associated with SRH. Among these, all associations were in the expected direction, except alcohol consumption: drinking twice a day was associated with better SRH compared to drinking once a day and less. Never drinking alcohol was associated in the expected direction, i.e. with higher SRH. Eight health status variables were not significantly associated with SRH, though six of these had coefficients in the expected direction.

\section{Maximising construct validity equivalence between the three forms of SRH}

Considering the overall explained variance for men and women together, results showed that the linear scheme had the lowest variation between forms (standard deviation (SD) of overall explained variance $=1.94$ ) compared to the dichotomised with positive focus scheme (Table 3 ). However, the best coding scheme was different for men and women: SD of overall explained variance was the lowest for the linear 
Table 1 Sample characteristics for three self-rated health forms, Swiss Health Survey

\begin{tabular}{|c|c|c|c|c|}
\hline & $\begin{array}{l}\text { SRH form } 1^{*} \\
N(\%)\end{array}$ & $\begin{array}{l}\text { SRH form } 2^{*} \\
N(\%)\end{array}$ & $\begin{array}{l}\text { SRH form } 3 * \\
N(\%)\end{array}$ & $P$ \\
\hline \multicolumn{5}{|l|}{ Men } \\
\hline Survey periods & 2002 & 2007 & 2012 & \\
\hline Number of respondents & 8620 & 8097 & 9859 & \\
\hline Age, mean (SD) & $48.6(16.9)$ & $49.6(17.3)$ & $49.1(17.8)$ & 0.11 \\
\hline $\begin{array}{l}\text { Marital status } \\
\text { Single } \\
\text { Married } \\
\text { Widowed } \\
\text { Divorced and separated }\end{array}$ & $\begin{array}{l}2288(26.5) \\
5234(60.7) \\
353(4.1) \\
743(8.6)\end{array}$ & $\begin{array}{l}2234(27.6) \\
4645(57.4) \\
360(4.4) \\
851(10.5)\end{array}$ & $\begin{array}{l}2898(29.4) \\
5951(60.4) \\
266(2.7) \\
7336(7.5)\end{array}$ & $<0.001$ \\
\hline $\begin{array}{l}\text { Number of children younger than } 15 \text { living in the household } \\
0 \\
1 \\
2 \\
3 \text { and more }\end{array}$ & $\begin{array}{l}6336(73.5) \\
892(10.3) \\
1042(12.1) \\
350(4.1)\end{array}$ & $\begin{array}{l}6191(76.5) \\
764(9.4) \\
848(10.5) \\
294(3.6)\end{array}$ & $\begin{array}{l}6964(70.7) \\
1300(13.2) \\
1175(11.9) \\
413(4.2)\end{array}$ & $<0.001$ \\
\hline $\begin{array}{l}\text { Citizenship } \\
\text { Swiss } \\
\text { Other }\end{array}$ & $\begin{array}{l}7483(86.8) \\
1137(13.2)\end{array}$ & $\begin{array}{l}6909(85.4) \\
1184(14.6)\end{array}$ & $\begin{array}{l}8019(81.3) \\
1840(18.7)\end{array}$ & $<0.001$ \\
\hline $\begin{array}{l}\text { Education } \\
\text { Primary } \\
\text { Secondary } \\
\text { Tertiary }\end{array}$ & $\begin{array}{l}1121(13.0) \\
5305(61.6) \\
2182(25.3)\end{array}$ & $\begin{array}{l}758(9.4) \\
4585(56.7) \\
2750(34.0)\end{array}$ & $\begin{array}{l}1252(12.8) \\
4953(50.5) \\
3598(36.7)\end{array}$ & $<0.001$ \\
\hline $\begin{array}{l}\text { Household monthly income (CHF) } \\
\text { Less than } 3000 \\
3000-6000 \\
6001-9000 \\
\text { More than } 9000\end{array}$ & $\begin{array}{l}2231(27.0) \\
4715(57.0) \\
1029(12.4) \\
292(3.5)\end{array}$ & $\begin{array}{l}2475(31.4) \\
3940(50.0) \\
1042(13.2) \\
421(5.3)\end{array}$ & $\begin{array}{l}2063(21.7) \\
5465(57.6) \\
1401(14.8) \\
564(5.9)\end{array}$ & $<0.001$ \\
\hline $\begin{array}{l}\text { Employment } \\
\text { Out of labour force } \\
\text { Employed full time } \\
\text { Employed part time }\end{array}$ & $\begin{array}{l}2403(28.2) \\
5503(64.5) \\
630(7.4)\end{array}$ & $\begin{array}{l}2333(29.1) \\
4903(61.2) \\
778(9.7)\end{array}$ & $\begin{array}{l}2683(27.5) \\
6071(62.1) \\
1018(10.4)\end{array}$ & $<0.001$ \\
\hline $\begin{array}{l}\text { Urban area } \\
\text { Urban } \\
\text { Rural }\end{array}$ & $\begin{array}{l}6131(71.1) \\
2489(28.9)\end{array}$ & $\begin{array}{l}5457(67.4) \\
2640(32.6)\end{array}$ & $\begin{array}{l}7012(71.1) \\
2847(28.9)\end{array}$ & $<0.001$ \\
\hline $\begin{array}{l}\text { Linguistic area } \\
\text { German speaking } \\
\text { French speaking } \\
\text { Italian speaking }\end{array}$ & $\begin{array}{l}5901(68.5) \\
2052(23.8) \\
667(7.7)\end{array}$ & $\begin{array}{l}5001(61.8) \\
2462(30.4) \\
634(7.8)\end{array}$ & $\begin{array}{l}6614(67.1) \\
2537(25.7) \\
708(7.2)\end{array}$ & $<0.001$ \\
\hline Use of medicine over the past 7 days & $3348(38.9)$ & $3669(45.4)$ & $4542(46.1)$ & $<0.001$ \\
\hline $\begin{array}{l}\text { Having friends or relatives to discuss personal issues } \\
\text { Women }\end{array}$ & $7520(94.3)$ & $7108(93.4)$ & $9040(95.6)$ & $<0.001$ \\
\hline Survey periods & 2002 & 2007 & 2012 & \\
\hline Number of respondents & 10,510 & 10,059 & 10,878 & \\
\hline Age, mean (SD) & $50.6(17.4)$ & $51.6(18.0)$ & $49.9(17.8)$ & 0.005 \\
\hline $\begin{array}{l}\text { Marital status } \\
\text { Single } \\
\text { Married } \\
\text { Widow } \\
\text { Divorced and separated }\end{array}$ & $\begin{array}{l}2322(22.1) \\
5505(52.4) \\
1450(13.8) \\
1228(11.7)\end{array}$ & $\begin{array}{l}2323(23.1) \\
4904(48.8) \\
1521(15.1) \\
1302(13)\end{array}$ & $\begin{array}{l}2625(24.2) \\
5943(54.7) \\
1009(9.3) \\
1291(11.9)\end{array}$ & $<0.001$ \\
\hline $\begin{array}{l}\text { Citizenship } \\
\text { Swiss } \\
\text { Other }\end{array}$ & $\begin{array}{l}9331(88.8) \\
1179(11.2)\end{array}$ & $\begin{array}{l}8884(88.4) \\
1169(11.6)\end{array}$ & $\begin{array}{l}9205 \text { (84.6) } \\
1673(15.4)\end{array}$ & $<0.001$ \\
\hline $\begin{array}{l}\text { Education } \\
\text { Primary } \\
\text { Secondary } \\
\text { Tertiary }\end{array}$ & $\begin{array}{l}2573(24.5) \\
6889(65.7) \\
1030(9.8)\end{array}$ & $\begin{array}{l}1793(17.8) \\
6230(62.0) \\
2027(20.2)\end{array}$ & $\begin{array}{l}1815(16.8) \\
6558(60.6) \\
2454(22.7)\end{array}$ & $<0.001$ \\
\hline
\end{tabular}


Table 1 (continued)

\begin{tabular}{|c|c|c|c|c|}
\hline & $\begin{array}{l}\text { SRH form } 1^{*} \\
N(\%)\end{array}$ & $\begin{array}{l}\text { SRH form } 2 * \\
N(\%)\end{array}$ & $\begin{array}{l}\text { SRH form 3* } \\
N(\%)\end{array}$ & $P$ \\
\hline $\begin{array}{l}\text { Number of children younger than } 15 \text { living in the household } \\
0 \\
1 \\
2 \\
3 \text { and more }\end{array}$ & $\begin{array}{l}7941(75.6) \\
1026(9.8) \\
1134(10.8) \\
408(3.9)\end{array}$ & $\begin{array}{l}7730(76.8) \\
996(9.9) \\
1018(10.1) \\
315(3.1)\end{array}$ & $\begin{array}{l}7621(70.1) \\
1499(13.8) \\
1287(11.8) \\
465(4.3)\end{array}$ & $<0.001$ \\
\hline $\begin{array}{l}\text { Income } \\
\text { Less than } 3000 \\
3000-6000 \\
6001-9000 \\
\text { More than } 9000\end{array}$ & $\begin{array}{l}3322(34.1) \\
5541(56.9) \\
712(7.3) \\
162(1.7)\end{array}$ & $\begin{array}{l}3569(37.9) \\
4885(51.9) \\
763(8.1) \\
203(2.2)\end{array}$ & $\begin{array}{l}2681(26.6) \\
5988(59.5) \\
1142(11.3) \\
258(2.6)\end{array}$ & $<0.001$ \\
\hline \multicolumn{5}{|l|}{ Employment } \\
\hline $\begin{array}{l}\text { Out of labour force } \\
\text { Employed full time } \\
\text { Employed part time }\end{array}$ & $\begin{array}{l}4952(48.2) \\
2329(22.7) \\
2997(29.2)\end{array}$ & $\begin{array}{l}4548(46.6) \\
2180(22.3) \\
3042(31.1)\end{array}$ & $\begin{array}{l}4174(39.0) \\
2612(24.4) \\
3909(36.5)\end{array}$ & $<0.001$ \\
\hline \multicolumn{5}{|l|}{ Urban area } \\
\hline $\begin{array}{l}\text { Urban } \\
\text { Rural }\end{array}$ & $\begin{array}{l}7721(73.5) \\
2788(26.5)\end{array}$ & $\begin{array}{l}7011(69.7) \\
3048(30.3)\end{array}$ & $\begin{array}{l}7823(71.9) \\
3055(28.1)\end{array}$ & 0.001 \\
\hline \multicolumn{5}{|l|}{ Linguistic area } \\
\hline $\begin{array}{l}\text { German speaking } \\
\text { French speaking } \\
\text { Italian speaking }\end{array}$ & $\begin{array}{l}6936(66.0) \\
2720(25.9) \\
853(8.1)\end{array}$ & $\begin{array}{l}6109(60.7) \\
3084(30.7) \\
866(8.6)\end{array}$ & $\begin{array}{l}7113(65.4) \\
2926(26.9) \\
839(7.7)\end{array}$ & $<0.001$ \\
\hline Use of medicine over the past 7 days & $5156(49.1)$ & $5617(55.9)$ & $5829(53.6)$ & $<0.001$ \\
\hline Having friends or relatives to discuss personal issues & $9711(95.4)$ & $9249(95.4)$ & $10,075(95.9)$ & 0.09 \\
\hline
\end{tabular}

$S R H$ self-rated health

"Form 1: "Let's start with the basics. How are you doing today?", response options: very good, good, okay (moderate), bad, very bad;

Form 2: "How is your health in general?", response options: very good, good, moderate, bad, very bad;

Form 3: "How is your health status in general? Would you say it is...", response options: very good, good, relatively good, bad, very bad

scheme for men (SD 1.96) and for the dichotomised with positive focus scheme for women (SD 1.72).

For specific health dimensions, results were heterogeneous. In the full sample, SD of explained variance was the lowest in the dichotomised with negative focus scheme for all health dimensions except the dimension of health behaviours. A similar pattern was observed when stratifying the results between men and women, with the exception of physical health.

\section{Sensitivity analyses}

First, analyses including respondents from waves 1992 and 1997 showed similar findings (data not shown), i.e. nonequivalence between forms, and form 3 with the best overall explained variance. Second, analyses stratified by age groups (18-35, 36-59 and 60+) showed also similar findings with main analysis (data not shown). In terms of the coding scheme maximising the equivalence across forms, no clear pattern emerged from the results, with the exception that the dichotomised with positive focus scheme maximised equivalence among respondents aged 36-59. Twenty-three and 26 health status variables were significantly associated with SRH among respondents $18-35$ and 36-59, respectively. These associations were in the excepted direction, with a few exceptions. Among respondents aged $60+, 17$ health status variables were significantly associated with $\mathrm{SRH}$, and these associations were in the expected direction. Among the 17 health status variables not significantly associated with SRH, 11 of them had a coefficient in the expected direction and 6 in the unexpected direction. Third, analyses stratified by education groups showed similar findings with main analysis (non-equivalence between forms, form 3 with the best overall explained variance) for the three educational groups (data not shown). In terms of the coding scheme maximising the equivalence across forms, no clear pattern emerged from the results, except among respondents with secondary education where the dichotomised with positive focus scheme maximised equivalence. Twenty-nine and 25 health status variables were significantly associated with SRH among respondents with secondary and tertiary education, respectively, and these associations were in the excepted direction, with a few exceptions. Among respondents with primary education, 13 health status variables were significantly associated with 
Fig. 1 Distribution for each form of the SRH item. SRH self-rated health. Source: Swiss Health Survey

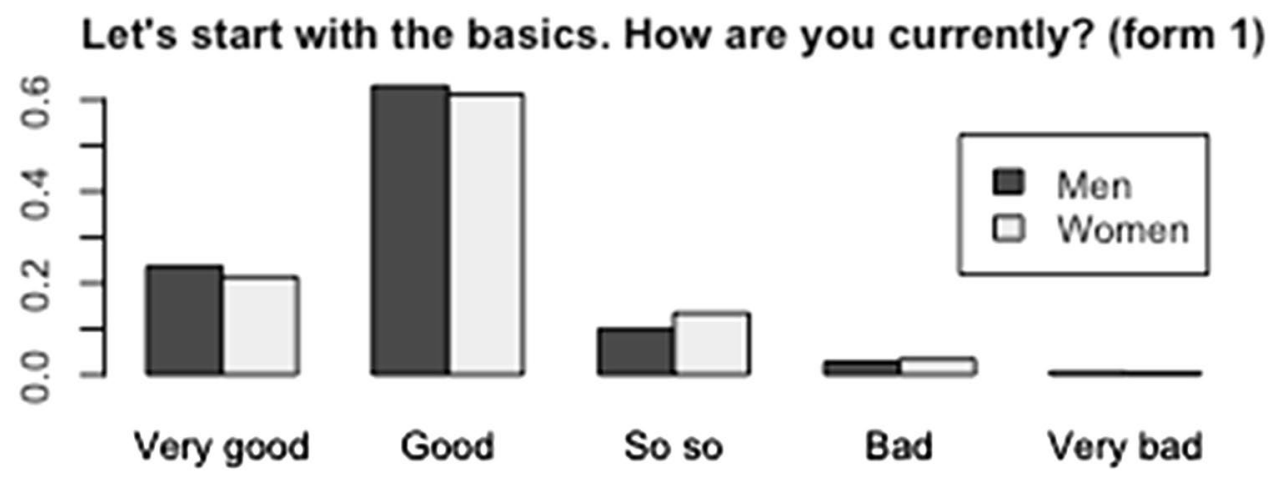

How is your overall health? (form 2)
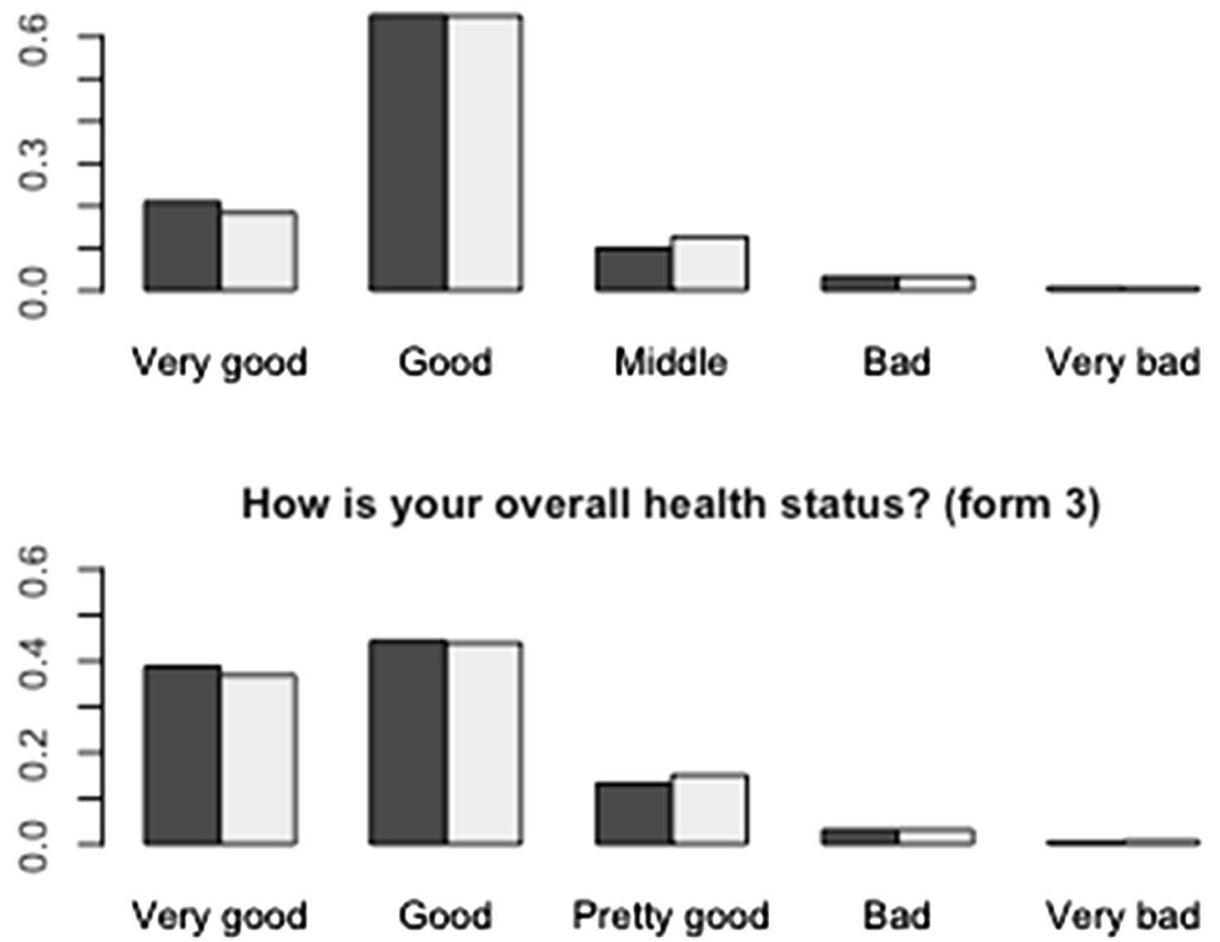

$\mathrm{SRH}$, and these associations were in the expected direction. Twenty-one health status variables were not associated with SRH; however, almost all of these were associated in the expected direction. Similarly to main the analysis, alcohol consumption was associated with $\mathrm{SRH}$ in the unexpected direction across all age and education groups.

\section{Discussion}

The first objective of this study was to examine if the construct validity of three forms of the SRH item is equivalent. Differences in the percentages of the overall explained variance suggested that the three forms were not equivalent in their ability to capture respondents' general health. The overall percentage of explained variance was $12.7 \%$ in form $1,10.0 \%$ in form 2 and $14.2 \%$ in form 3. This difference was similar when using different coding schemes. When considering the association between different health dimensions and the SRH item, however, the lack of equivalence was less pronounced. Functional health was the dimension with the best, almost strict, equivalence across forms: for this dimension, differences across the forms were systematically less than $1 \%$, regardless of coding schemes. In other words, respondents were not influenced by the form of the SRH when assessing the functional aspect of their health, like their autonomy (walking, reading and hearing). Conversely, mental health was the dimension with the worst equivalence across forms: differences of explained variances 
Table 2 Percentages of explained variance of three forms of self-rated health, overall and by health dimensions, by four coding schemes

\begin{tabular}{|c|c|c|c|c|}
\hline & SRH form 1 & SRH form 2 & SRH form 3 & $\begin{array}{l}\text { Largest difference } \\
\text { across three SRH } \\
\text { forms }\end{array}$ \\
\hline \multicolumn{5}{|c|}{$\begin{array}{l}\text { Dichotomised with posi- } \\
\text { tive focus coding: }\end{array}$} \\
\hline \multicolumn{5}{|c|}{$\begin{array}{l}\text { Very bad, bad, moderate } \\
\text { versus good, very good }\end{array}$} \\
\hline Overall & $12.7 \%$ & $10.0 \%$ & $14.2 \%$ & $4.2 \%$ \\
\hline Physical health & $6.9 \%$ & $5.5 \%$ & $7.4 \%$ & $1.9 \%$ \\
\hline Chronic diseases & $1.9 \%$ & $1.7 \%$ & $2.5 \%$ & $0.8 \%$ \\
\hline Mental health & $6.7 \%$ & $4.8 \%$ & $7.6 \%$ & $2.8 \%$ \\
\hline Functional health & $0.6 \%$ & $0.4 \%$ & $0.5 \%$ & $0.2 \%$ \\
\hline Health behaviours & $2.2 \%$ & $2.1 \%$ & $2.6 \%$ & $0.5 \%$ \\
\hline \multicolumn{5}{|c|}{$\begin{array}{l}\text { Dichotomised with nega- } \\
\text { tive focus coding: }\end{array}$} \\
\hline \multicolumn{5}{|l|}{$\begin{array}{l}\text { Very bad, bad versus } \\
\text { moderate, good, very } \\
\text { good }\end{array}$} \\
\hline Overall $^{\mathrm{a}}$ & - & - & - & - \\
\hline Physical health & $1.7 \%$ & $1.3 \%$ & $1.3 \%$ & $0.4 \%$ \\
\hline Chronic diseases & $0.2 \%$ & $0.0 \%$ & $0.0 \%$ & $0.2 \%$ \\
\hline Mental health & $2.1 \%$ & $0.6 \%$ & $2.2 \%$ & $1.6 \%$ \\
\hline Functional health & $0.0 \%$ & $0.0 \%$ & $0.0 \%$ & $0.0 \%$ \\
\hline Health behaviours & $3.0 \%$ & $1.4 \%$ & $3.9 \%$ & $2.5 \%$ \\
\hline \multicolumn{5}{|l|}{ Linear $^{\mathrm{b}}$ coding } \\
\hline Overall & $14.1 \%$ & $12.9 \%$ & $16.7 \%$ & $3.8 \%$ \\
\hline Physical health & $8.0 \%$ & $7.4 \%$ & $9.3 \%$ & $1.9 \%$ \\
\hline Chronic diseases & $2.8 \%$ & $3.2 \%$ & $4.1 \%$ & $1.3 \%$ \\
\hline Mental health & $8.1 \%$ & $6.7 \%$ & $10.0 \%$ & $3.3 \%$ \\
\hline Functional health & $1.3 \%$ & $1.9 \%$ & $1.2 \%$ & $0.7 \%$ \\
\hline Health behaviours & $1.5 \%$ & $1.5 \%$ & $2.7 \%$ & $1.2 \%$ \\
\hline \multicolumn{5}{|l|}{ Linearised $^{\mathrm{c}}$ coding } \\
\hline Overall & - & - & $21.8 \%$ & - \\
\hline Physical health & - & - & $12.6 \%$ & - \\
\hline Chronic diseases & - & - & $4.9 \%$ & - \\
\hline Mental health & - & - & $13.3 \%$ & - \\
\hline Functional health & - & - & $2.1 \%$ & - \\
\hline Health behaviours & - & - & $3.1 \%$ & - \\
\hline
\end{tabular}

SRH self-rated health. Source: Swiss Health Survey

Adjusted R squared for linear coding scheme, MacKelvey and Zavoina pseudo R squared for dichotomous coding schemes. All models were adjusted for age, gender, marital status, number of children, nationality, education, income, employment status, urban vs. rural area, linguistic region, use of medicine in the last 7 days, having friends or relatives to discuss personal issues

aModel for "overall" when SRH was coded "dichotomised with negative focus" was not estimated because the ratio between the degrees of freedom and the sample size was lower than 10—see "Statistical analysis" section

${ }^{\mathrm{b}}$ Linear $=$ Response options coded $1-5$

"Linearised = Response options coded "evenly" spaced: 1, 2, 3.7, 4.5, 5. The linearised coding scheme can be used with form 3 only—see "Method" section across forms were systematically above $1 \%$ across coding schemes, with a largest difference of $3.8 \%$ for linear coding. In other words, change in SRH forms may influence the way respondents are assessing the mental aspect of their general health, like their sleep quality, sense of control, feeling of tiredness, etc.

The second objective of this study was to determine which form had the best construct validity. Form 3 ("How 
Table 3 Standard deviation of percentages of explained variance of self-rated health forms, by coding schemes, adjusted

\begin{tabular}{|c|c|c|c|}
\hline & \multicolumn{3}{|l|}{ Coding schemes } \\
\hline & $\begin{array}{l}\text { Dichotomised with positive } \\
\text { focus } \\
\text { (very bad, bad, moderate versus } \\
\text { good, very good) }\end{array}$ & $\begin{array}{l}\text { Dichotomised with negative } \\
\text { focus } \\
\text { (very bad, bad versus moderate, } \\
\text { good, very good) }\end{array}$ & Lineara $^{\mathrm{a}}$ \\
\hline All & SD & SD & SD \\
\hline Overall & 2.13 & - & 1.94 \\
\hline Physical health & 0.99 & 0.23 & 0.97 \\
\hline Chronic diseases & 0.42 & 0.12 & 0.67 \\
\hline Mental health & 1.43 & 0.90 & 1.66 \\
\hline Functional health & 0.10 & 0.00 & 0.38 \\
\hline Health behaviours & 0.26 & 1.27 & 0.69 \\
\hline \multicolumn{4}{|l|}{ Men } \\
\hline Overall & 2.04 & - & 1.96 \\
\hline Physical health & 1.08 & 0.92 & 0.85 \\
\hline Chronic diseases & 0.59 & 0.06 & 0.93 \\
\hline Mental health & 1.35 & 0.64 & 1.30 \\
\hline Functional health & 0.20 & 0.00 & 0.61 \\
\hline Health behaviours & 0.53 & 1.79 & 0.85 \\
\hline \multicolumn{4}{|l|}{ Women } \\
\hline Overall & 1.72 & - & 1.95 \\
\hline Physical health & 0.90 & 0.98 & 1.04 \\
\hline Chronic diseases & 0.21 & 0.21 & 0.47 \\
\hline Mental health & 1.36 & 1.01 & 1.96 \\
\hline Functional health & 0.12 & 0.00 & 0.20 \\
\hline Health behaviours & 0.40 & 0.86 & 0.59 \\
\hline
\end{tabular}

$S D$ standard deviation. Source: Swiss Health Survey

For age, gender, marital status, number of children, nationality, education, income, employment status, urban vs. rural area, linguistic region, use of medicine in the last 7 days, having friends or relatives to discuss personal issues

${ }^{\mathrm{a}}$ Linear $=$ Response options coded $1-5$ is your health status in general? Would you say it is...") had the best construct validity compared to forms 1 and 2 , since it had the highest percentage of explained variance. This result holds when using two different coding schemes (linear and dichotomised with positive focus) and when looking across health dimensions of SRH items. This finding is expected because form 3 has a clearer, more focused, question about health in general compared to form 1 ("How are you doing today?"). Form 1 relates to a general inquiry about how life is going, or someone's health, or someone's actual emotional makeup, or someone's satisfaction with life. Form 2 ("How is your health in general?") is the closest to the frequently used form in national surveys and epidemiological studies (form 9 in Table S1). Two differences characterise form 2 and form 3. First, form 3 focuses on "health status" while form 2 focuses on "health" alone. Second, form 3 contrasts three positive response options against two negative options, also called the "US version", while form 2 is more balanced by contrasting two positive, one neutral, and two negative options, also called the "WHO version" [14]. In high-income countries, where prevalence of good general health is high, giving respondents three shades of positive ratings may be more appropriate to capture inter-individual variability, in contrary to middle- and low-income countries, where prevalence of poor health suggests to prefer the WHO version [2].

A striking finding was the good performance of form 1 ("Let's start with the basics. How are you doing today?"). At first glance, this form potentially steers away from a question assessing health status but, in our results, it performed better compared to form 2 ("How is your health in general?"), one of the most commonly used form in health research (see Table S1). This finding supports the hypothesis that form 1 of the SRH item may be an indicator of general well-being [40, 41].

We also showed that transforming the numerical distribution of response options into a way that linearised the intervals between the five options [18] allowed to increase the explained variance. This transformation only applied to form 3, which sets up three positive statements against two 
negatives. Such transformation is simple, improves statistical analysis, allows keeping respondents' answer in their original response options (instead of dichotomising response options), and improves the interpretation of mean values of SRH in populations groups [18].

The third objective of this study was to determine the coding scheme maximizing the equivalence across the three forms, to improve comparison across SHS waves. Based on the results, we advise using the linear coding scheme which had the lowest variation across forms in the proportion of explained variance in SRH by 34 health variables. In other words, studies wanting to use the SRH item across different waves (trend studies) [42] should treat this item as a continuous variable instead of a dichotomous one. However, this recommendation may not apply to studies examining one gender only: in a study of women, the dichotomous coding scheme with negative focus (very bad, bad, moderate $v s$. good, very good) is recommended to maximise the equivalence between forms of the SRH.

The above findings are robust in the sense that we used a large sample size, the quality of the data from the SHS was high, and the explained variance was adjusted for demographics, socio-economic and family factors associated with SRH [19, 26-30]. Our main findings were also confirmed by two sensitivity analyses, one by age groups and one by educational groups. However, sensitivity analyses did not confirm the finding that using the linear coding scheme should maximise the equivalence between forms of the SRH: it was not true for the 36-59 years old and the secondary educated, for whom the best coding scheme was the dichotomous with positive focus; and for maximising the equivalence across SRH forms, using the dichotomous coding scheme with negative focus is recommended for studies on women. Similarly, sensitivity analyses suggested that construct validity of the best form (form 3 ) was a bit lower among vulnerable or disadvantaged people, like the $60+$ and those with primary education, a result in line with other studies [34, 43]. At the same time, several limitations of our study have to be considered. First, our findings suffer from lack of time synchronicity between waves (so between the different SRH forms). However, all models were adjusted with numerous sociodemographic and socioeconomic covariates to minimise this lack of temporal synchronicity. Second, the study has been conducted in one single country, Switzerland, thus its generalisability is subject to caution. However, studies have suggested construct validity of SRH was similar across very different countries [2]. Third, almost all SRH's covariates, be they health factors, health behaviours, health problems, demographic characteristics, socioeconomic status, etc., were significantly different across waves. In the Swiss health interview data, the 3 forms of SRH have been used at different waves, so waves and SRH forms are confounded. Because we do not have different SRH forms measured synchronously (during the same year), it is impossible to disentangle the effect of time change from the effect of different SRH forms. Finally, we used adjusted coefficients of determination ( $R$ squared when SRH was treated as a linear variable, MacKelvey and Zavoina pseudo $R$ squared when SRH was treated dichotomous) to assess relative construct validity. However, the comparison does not include a p-value to determine which scheme was significantly more informative than another, and thus our comparison is more qualitative than inferential.

In conclusion, the three forms of the SRH item in the SHS were not equivalent in terms of their relationships with other health measures. Institutions conducting repeated population health and demographic surveys and using this item should strive to keep the SRH item similar across waves. The form with the best construct validity was "How is your health status in general?". For studies aiming at examining the evolution of SRH over time, the linear coding scheme was the best option to maximise equivalence between SRH forms for the overall population. However, other coding performed better for subgroups and thus different coding options should systematically be investigated.

Funding This work was supported by the Swiss Cancer League Grant KLS-3144-02-2013.

Data availability This study used the data from the five waves of the Swiss Health Survey. Data are available for fee (1500 Swiss Francs, plus $8.0 \%$ tax) and users must request permission from the Swiss Federal Statistical Office (sgb12@bfs.admin.ch). Data must be destroyed after five years.

\section{Compliance with ethical standards}

Conflict of interest All authors declare that they have no conflict of interest.

Ethical statement Ethical approval has been obtained by the Swiss Federal Statistical Office.

Open Access This article is licensed under a Creative Commons Attribution 4.0 International License, which permits use, sharing, adaptation, distribution and reproduction in any medium or format, as long as you give appropriate credit to the original author(s) and the source, provide a link to the Creative Commons licence, and indicate if changes were made. The images or other third party material in this article are included in the article's Creative Commons licence, unless indicated otherwise in a credit line to the material. If material is not included in the article's Creative Commons licence and your intended use is not permitted by statutory regulation or exceeds the permitted use, you will need to obtain permission directly from the copyright holder. To view a copy of this licence, visit http://creativecommons.org/licenses/by/4.0/. 


\section{References}

1. DeSalvo, K. B., Fisher, W., Tran, K., Bloser, N., Merrill, W., \& Peabody, J. (2006). Assessing measurement properties of two single-item general health measures. Quality of Life Research, 15(2), 191-201. https://doi.org/10.1007/s11136-005-0887-2.

2. Cullati, S., Mukhopadhyay, S., Sieber, S., Chakraborty, A., \& Burton-Jeangros, C. (2018). Is the single self-rated health item reliable in India? A construct validity study. BMJ Global Health. https://doi.org/10.1136/bmjgh-2018-000856.

3. Cox, B., Oyen, H., Cambois, E., Jagger, C., Roy, S., Robine, J.-M., et al. (2009). The reliability of the Minimum European Health Module. International Journal of Public Health, 54(2), 55-60. https://doi.org/10.1007/s00038-009-7104-y.

4. Boardman, J. D. (2006). Self-rated health among U.S. adolescents. Journal of Adolescent Health, 38(4), 401-408. https://doi. org/10.1016/j.jadohealth.2005.01.006.

5. DeSalvo, K. B., Bloser, N., Reynolds, K., He, J., \& Muntner, P. (2006). Mortality prediction with a single general self-rated health question a meta-analysis. Journal of General Internal Medicine, 21(3), 267-275. https://doi.org/10.1111/j.1525-1497.2005.00291 . $\mathrm{x}$.

6. Idler, E. L., \& Benyamini, Y. (1997). Self-rated health and mortality: A review of twenty-seven community studies. Journal of Health and Social Behavior, 38(1), 21-37.

7. Halford, C., Wallman, T., Welin, L., Rosengren, A., Bardel, A., Johansson, S., et al. (2012). Effects of self-rated health on sick leave, disability pension, hospital admissions and mortality. A population-based longitudinal study of nearly 15,000 observations among Swedish women and men. BMC Public Health, 12, 1103. https://doi.org/10.1186/1471-2458-12-1103.

8. DeSalvo, K. B., Jones, T. M., Peabody, J., McDonald, J., Fihn, S., Fan, V., et al. (2009). Health care expenditure prediction with a single item, self-rated health measure. Medical Care. https://doi. org/10.1097/MLR.0b013e318190b716.

9. Jylhä, M. (2009). What is self-rated health and why does it predict mortality? Towards a unified conceptual model. Social Science \& Medicine, 69(3), 307-316. https://doi.org/10.1016/j.socsc imed.2009.05.013.

10. Shooshtari, S., Menec, V., \& Tate, R. (2007). Comparing predictors of positive and negative self-rated health between younger (25-54) and older (55+) Canadian adults. Res Aging, 29(6), 512554. https://doi.org/10.1177/0164027507305729.

11. Perruccio, A. V., Katz, J. N., \& Losina, E. (2012). Health burden in chronic disease: multimorbidity is associated with self-rated health more than medical comorbidity alone. Journal of Clinical Epidemiology, 65(1), 100-106. https://doi.org/10.1016/j.jclin epi.2011.04.013.

12. Yamada, C., Moriyama, K., \& Takahashi, E. (2012). Self-rated health as a comprehensive indicator of lifestyle-related health status. Environmental Health and Preventive Medicine, 17(6), 457-462. https://doi.org/10.1007/s12199-012-0274-x.

13. Bowling, A., \& Windsor, J. (2008). The effects of question order and response-choice on self-rated health status in the English Longitudinal Study of Ageing (ELSA). Journal of Epidemiology and Community Health, 62(1), 81-85. https://doi.org/10.1136/ jech.2006.058214.

14. Jürges, H., Avendano, M., \& Mackenbach, J. P. (2008). Are different measures of self-rated health comparable? An assessment in five European countries. European Journal of Epidemiology, 23(12), 773-781. https://doi.org/10.1007/s10654-008-9287-6.

15. Hernández-Quevedo, C., Jones, A. M., \& Rice, N. (2005). Reporting bias and heterogeneity in self-assessed health. Evidence from the British Household Panel Survey. The University of York, Health, Econometrics and Data Group Working Paper 05/04.
16. Garbarski, D., Schaeffer, N. C., \& Dykema, J. (2015). The effects of response option order and question order on self-rated health. Quality of Life Research, 24(6), 1443-1453. https://doi. org/10.1007/s11136-014-0861-y.

17. Garbarski, D., Schaeffer, N. C., \& Dykema, J. (2016). The effect of response option order on self-rated health: A replication study. Quality of Life Research, 25(8), 2117-2121. https://doi. org/10.1007/s11136-016-1249-y.

18. Perneger, T. V., Gayet-Ageron, A., Courvoisier, D. S., Agoritsas, T., \& Cullati, S. (2013). Self-rated health: Analysis of distances and transitions between response options. Quality of Life Research, 22(10), 2761-2768. https://doi.org/10.1007/s1113 6-013-0418-5.

19. Cullati, S., Rousseaux, E., Gabadinho, A., Courvoisier, D. S., \& Burton-Jeangros, C. (2014). Factors of change and cumulative factors in self-rated health trajectories: A systematic review. Advance Life Course Research, 19, 14-27. https://doi. org/10.1016/j.alcr.2013.11.002.

20. Bombak, A. E., \& Bruce, S. G. (2012). Self-rated health and ethnicity: focus on indigenous populations. International Journal of Circumpolar Health, 71(1), 18538. https://doi.org/10.3402/ ijch.v71i0.18538.

21. Roberts, G. (1999). Age effects and health appraisal: A metaanalysis. The Journals of Gerontology: Series B, 54B(1), S24S30. https://doi.org/10.1093/geronb/54B.1.S24.

22. Gunasekara, F. I., Carter, K., \& Blakely, T. (2011). Change in income and change in self-rated health: Systematic review of studies using repeated measures to control for confounding bias. Social Science \& Medicine, 72(2), 193-201. https://doi. org/10.1016/j.socscimed.2010.10.029.

23. Manderbacka, K. (1998). Examining what self-rated health question is understood to mean by respondents. [Research Support, Non-U.S. Gov't]. Scandinavian Journal of Social Medicine, 26(2), 145-153.

24. Simon, J. G., De Boer, J. B., Joung, I. M. A., Bosma, H., \& Mackenbach, J. P. (2005). How is your health in general? A qualitative study on self-assessed health. Eur J Public Health, 15(2), 200-208. https://doi.org/10.1093/eurpub/cki102.

25. WHO (1946). Preamble to the Constitution of the World Health Organization as adopted by the International Health Conference, New York, 19-22 June, 1946. Geneva: World Health Organization. Retrieved from http://www.who.int/about/definition/en/ print.html. Accessed Sep 01, 2007.

26. Cullati, S. (2015). Socioeconomic inequalities in health trajectories in Switzerland: are trajectories diverging as people age? Sociology of Health and Illness, 37(5), 745-764. https://doi. org/10.1111/1467-9566.12232.

27. Roberts, G. (1999). Age effects and health appraisal: A metaanalysis. The Journals of Gerontology Series B: Psychological Sciences and Social Sciences, 54B(1), S24-S30. https://doi. org/10.1093/geronb/54B.1.S24.

28. Sarti, S., \& Zella, S. (2016). Changes in the labour market and health inequalities during the years of the recent economic downturn in Italy. Social Science Research, 57, 116-132. https ://doi.org/10.1016/j.ssresearch.2015.12.010.

29. Gilbert, K. L., Quinn, S. C., Goodman, R. M., Butler, J., \& Wallace, J. (2013). A meta-analysis of social capital and health: A case for needed research. J Health Psychol, 18(11), 1385-1399. https://doi.org/10.1177/1359105311435983.

30. Della Bella, S., Lucchini, M., \& Assi, J. (2012). Health inequality across time: A growth curve analysis of self assessed health in contemporary Switzerland. Swiss Journal of Sociology, 32(2), 291-309.

31. Benyamini, Y., Leventhal, E. A., \& Leventhal, H. (2000). Gender differences in processing information for making 
self-assessments of health. Psychosomatic Medicine, 62(3), 354-364.

32. Idler, E. L. (2003). Discussion: Gender differences in self-rated health, in mortality, and in the relationship between the two. The Gerontologist, 43(3), 372-375. https://doi.org/10.1093/geron $\mathrm{t} / 43.3 .372$.

33. Courvoisier, D. S., Combescure, C., Agoritsas, T., Gayet-Ageron, A., \& Perneger, T. V. (2011). Performance of logistic regression modeling: Beyond the number of events per variable, the role of data structure. Journal of Clinical Epidemiology, 64(9), 9931000. https://doi.org/10.1016/j.jclinepi.2010.11.012.

34. Peersman, W., Cambier, D., De Maeseneer, J., \& Willems, S. (2012). Gender, educational and age differences in meanings that underlie global self-rated health. International Journal of Public Health, 57(3), 513-523. https://doi.org/10.1007/s0003 8-011-0320-2.

35. Layes, A., Asada, Y., \& Kepart, G. (2012). Whiners and deniersWhat does self-rated health measure? Social Science \& Medicine, 75(1), 1-9. https://doi.org/10.1016/j.socscimed.2011.10.030.

36. Maddox, G. L., \& Douglass, E. B. (1973). Self-assessment of health: A longitudinal study of elderly subjects. Journal of Health and Social Behavior, 14(1), 87-93.

37. Idler, E. L. (1993). Age differences in self-assessments of health: Age changes, cohort differences, or survivorship? Journal of Gerontology, 48(6), S289-S300. https://doi.org/10.1093/geron $\mathrm{j} / 48.6 . \mathrm{S} 289$.
38. Crossley, T. F., \& Kennedy, S. (2002). The reliability of selfassessed health status. Journal of Health Economics, 21(4), 643658. https://doi.org/10.1016/s0167-6296(02)00007-3.

39. Zajacova, A., \& Dowd, J. B. (2011). Reliability of Self-rated Health in US Adults. American Journal of Epidemiology, 174(8), 977-983. https://doi.org/10.1093/aje/kwr204.

40. Shields, M., \& Shooshtari, S. (2001). Determinants of self-perceived health. Health Reports, 13(1), 35-52.

41. Kaplan, G., \& Baron-Epel, O. (2003). What lies behind the subjective evaluation of health status? Social Science \& Medicine, 56(8), 1669-1676. https://doi.org/10.1016/s0277-9536(02)00179-x.

42. Volken, T., Wieber, F., Rüesch, P., Huber, M., \& Crawford, R. J. (2017). Temporal change to self-rated health in the Swiss population from 1997 to 2012: the roles of age, gender, and education. Public Health, 150, 152-165. https://doi.org/10.1016/j. puhe.2017.07.007.

43. Krause, N. M., \& Jay, G. M. (1994). What do global self-rated health items measure? Medical Care, 32(9), 930-942.

Publisher's Note Springer Nature remains neutral with regard to jurisdictional claims in published maps and institutional affiliations. 